\title{
O pequi no noticiário: análise dos resultados de uma pesquisa na busca do site Folha de S. Paulo
}

\author{
The pequi in the news: analysis of results of a research on site search Folha de $S$. \\ Paulo
}

\author{
Edison Trombeta de Oliveira ${ }^{1}$ \\ (edisontrombeta@gmail.com) \\ Danielli dos Santos Baeta ${ }^{2}$ \\ (danielli.baeta@gmail.com) \\ Marcos Barros de Souza ${ }^{3}$ \\ (souzamb@bol.com.br) \\ Olga Maria Mascarenhas de Faria Oliveira ${ }^{4}$ \\ (olgamascarenhaso@gmail.com) \\ http://dx.doi.org/10.5216/cei.v15i2.21812
}

\begin{abstract}
Resumo
Dentre as espécies frutíferas do Cerrado brasileiro, o pequi é muito popular nas regiões onde é extraído. Comumente utilizado em pratos típicos, na indústria medicinal, cosmética e na artesanal, também se estuda o seu potencial na produção de combustível. Assim, este artigo procurou ponderar sobre a divulgação deste fruto na imprensa, por meio do sistema de busca do site da Folha de S.Paulo e aplicando a análise de conteúdo, proposta por Bardin, além da pesquisa documental e bibliográfica. A justificativa para esta pesquisa é a de que o pequi é um fruto de grande importância na economia sustentável e, mesmo assim, pouco se fala sobre ele na grande mídia. Resulta daí que, pelo analisado, pouco se fala sobre o pequi na mídia e seu foco é, principalmente, o jornalismo cultural, na culinária.
\end{abstract}

Palavras-chave: Jornalismo. Folha de S.Paulo. Análise de Conteúdo. Pequi.

\begin{abstract}
Among the fruit species of the Brazilian Cerrado, the pequi is much popular in regions where it is extracted. Often it used in typical dishes, on the industry medicinal, cosmetic and handmade, also it studied its potential to produce fuel. Thus, this article sought to ponder about the disclosure of this fruit in the press, by means of the search system's site Folha de S. Paulo and applying content analysis, proposed by Bardin, beyond bibliography and documentary research. The justification for this research is that the pequi is a fruit of great

\footnotetext{
${ }^{1}$ Graduado em Comunicação Social - Habilitação Jornalismo pela Universidade do Oeste Paulista (Unoeste), com aperfeiçoamento em Leitura Semiótica: Textos Didáticos, Publicitários e Literários pela mesma instituição. É mestrando em Educação pela Faculdade de Ciências e Tecnologia da Universidade Estadual Paulista Júlio de Mesquita Filho (FCT/UNESP).

${ }^{2}$ Graduada em Química (Licenciatura) pela Faculdade de Ciências e Tecnologia da Universidade Estadual Paulista Júlio de Mesquita Filho (FCT/UNESP). É mestranda em Biotecnologia pelo Instituto de Química da Universidade Estadual Paulista Júlio de Mesquita Filho (IQ/UNESP).

${ }^{3}$ Graduado em Geografia (Licenciatura) e Geografia (Bacharelado) pela Faculdade de Ciências e Tecnologia da Universidade Estadual Paulista Júlio de Mesquita Filho (FCT/UNESP). Mestre e Doutor em Geografia (Geografia Física) pela Faculdade de Filosofia, Letras e Ciências Humanas da Universidade de São Paulo (USP).

${ }^{4}$ Graduada em Química (Licenciatura) pela Universidade Estadual Paulista Júlio de Mesquita Filho (UNESP). Doutora em Ciências Biológicas (Bioquímica) pela Universidade de São Paulo (USP). Livre-Docente em Ciências Biológicas (Bioquímica) pela Universidade Estadual Paulista Júlio de Mesquita Filho (UNESP). É Professor Adjunto junto ao Departamento de Bioquímica e Tecnologia Química do Instituto de Química da Universidade Estadual Paulista Júlio de Mesquita Filho (IQ/UNESP).
}

Comun. \& Inf., v. 15, n. 2, p. 4-13, jul./dez. 2012 
importance in the economy and sustainable, yet little is spoken about it in the mainstream media. The result is that, by the analysis, little is said about the pequi media and its focus, is principally, cultural journalism, in culinary.

Keywords: Journalism. Folha de S.Paulo. Content analysis. Pequi.

\section{Introdução}

O pequi é um fruto típico do Cerrado brasileiro e desempenha um importante papel na geração de renda de diversas cidades e comunidades do país. Medicamentos, combustíveis e gastronomia são algumas de suas aplicações e, por estas e outras particularidades, o fruto tem ganhado cada vez mais espaço na imprensa, por meio da divulgação científica e cultural em impressos diários, principalmente.

Um destes, que está entre os de maior circulação no Brasil, é a Folha de S.Paulo, periódico fundado em 1921 por Olival Costa e Pedro Cunha. Na média diária, são 296.288 exemplares, pelas estatísticas do mês de julho de 2012. Além disso, está entre os mais influentes do país, ao lado de $O$ Globo, Correio Brasiliense e O Estado de S.Paulo.

Tendo em vista a crescente importância do pequi na economia brasileira e a grande influência dos jornais diários, esta pesquisa questionou qual tem sido o foco da divulgação do fruto, tendo como base uma pesquisa na busca do site da Folha de S.Paulo, que permite pesquisas na seção "Jornal Impresso", com delimitação de data e, além disso, tem conteúdo disponível na internet de forma gratuita.

A hipótese inicial da investigação é a de que a divulgação do pequi na imprensa ainda é pouco constante e foca mais o seu uso na gastronomia, deixando de lado as demais utilizações do fruto. Há de se levar em consideração, por exemplo, que diversas pesquisas têm sido executadas de forma a possibilitar o uso do pequi enquanto biocombustível e, em outra área, na produção de remédios.

Desta forma, os objetivos da pesquisa envolveram a busca, quantificação e análise de notícias que falassem a respeito do pequi, a fim de se problematizar a respeito da divulgação do citado fruto. Além disso, buscou-se lançar luz sobre o fruto e pesquisas que tratem da importância dele nas mais diversas esferas da sociedade, enquanto um elemento importante no ciclo econômico do Brasil.

Para isso, a base epistemológica principal foi o postulado por Bardin (2002) na sua teoria da análise de conteúdo. Nela, busca-se analisar o material conseguido de forma a encontrar palavras e 
termos coincidentes, classificá-los e indicar o que representa esta repetição - ou não-repetição - de termos ou palavras. Além disso, a pesquisa bibliográfica traçou a base teórica da investigação, enquanto a documental teve como utilidade principal a procura e a seleção dos materiais a serem analisados.

Por fim, justifica-se a presente pesquisa principalmente por dois fatores: a crescente importância do fruto em diversos pontos da sociedade, como: economia, turismo, gastronomia e sustentabilidade; e, numa proporção ainda maior, a ascendente influência que os meios de comunicação de massas (entre os quais está o jornal) têm na formação do entendimento da realidade popular.

\section{0 fruto}

O Brasil possui a maior variedade biológica do planeta distribuída em seus diferentes ecossistemas, onde estão cerca de $30 \%$ das espécies de plantas e de animais conhecidas em todo o mundo (AVIDOS e FERREIRA, 2000). Segundo bioma brasileiro em extensão geográfica, ultrapassado apenas pela floresta Amazônica (PROENÇA, OLIVEIRA e SILVA, 2006), o Cerrado ocupa mais de dois milhões de quilômetros quadrados e uma extensa área contínua localizada no Brasil Central, além de algumas penínsulas e áreas disjuntas periféricas que se estendem por outros Estados.

Estudos que vêm sendo desenvolvidos apontam para o elevado potencial econômico do Cerrado, especialmente nas áreas de: alimentos (já se conhecem cerca de 80 espécies vegetais que fornecem frutos, sementes ou palmitos que servem para a alimentação do homem); produção de fibras; produção de cortiça (existem cerca de 20 espécies que já são utilizadas para esse fim); produção de tanino; produção de gomas, resinas e látex; produção de óleos e gorduras; uso medicinal (mais de 100 espécies vegetais são usadas para a cura e prevenção de doenças); plantas ornamentais; artesanato; e plantas apícolas (DIAS, 1992).

Nesta região há um considerável número de espécies com frutos comestíveis que são utilizados há muito tempo pelas populações locais. Essas frutas nativas, provenientes de atividades extrativistas, são comercializadas e consumidas in natura ou beneficiadas por indústrias caseiras em diversas formas, como doces, geleias, sorvetes, bolos, mingaus, biscoitos, pães e licores, com uma boa aceitação popular (BOAS, 2009; SILVA et al., 2008). Atente-se ao fato de que a maioria desses frutos possui altos teores de carboidratos, proteínas, vitaminas e sais minerais, além de sabores muito característicos (SILVA et al., 2008). 
Existem poucos estudos sobre a caracterização do valor nutricional da infinidade frutífera do Cerrado brasileiro (LIMA, 2008). Estudos sobre esses frutos quanto as suas características nutricionais, bem como sobre o desenvolvimento e aprimoramento de técnicas para agregação de valores nutricionais e econômicos, são fundamentais para a divulgação desses produtos e para a expansão da culinária local em níveis nacional e internacional, gerando meios sustentáveis de renda para as populações dessas regiões (BOAS, 2009; LIMA, 2008).

Dentre as espécies típicas desse bioma brasileiro, o pequizeiro é de ampla utilidade pela população, sendo considerado como 'rei do cerrado' (LIMA, 2008), isso devido ao seu valor alimentício, nutricional, ornamental, social e medicinal (KERR, SILVA e TCHCARRAMAE, 2007).

O pequi (Caryocar brasiliense Camb.), conhecido também como amêndoa de espinho, amêndoa do Brasil, grão de cavalo, pequerim, pequiá, pequiá-pedra, piqui, piquiá, piquiá-bravo ou suari, é cultivado em todo o Cerrado, que inclui os Estados da Bahia, Ceará, Goiás, Maranhão, Mato Grosso, Mato Grosso do Sul, Minas Gerais, Pará, Piauí, Rio de Janeiro e São Paulo (RIBEIRO, 2000). Este fruto é do tipo drupa, constituído: pelo exocarpo, que possui coloração esverdeada ou marrom-esverdeada; pelo mesocarpo externo, de coloração verde clara ou levemente amarela; pelo mesocarpo interno, porção comestível do fruto que possui coloração amarelada; e pelo endocarpo, parte espinhosa que protege a semente ou amêndoa. A semente, que também pode ser comestível, é revestida por um tegumento fino de coloração marrom (RIBEIRO, 2000; ARAÚJO, 1995).

A exploração do pequi é considerada uma prática ambientalmente sustentável, desde sua coleta, transporte, beneficiamento, comercialização até o consumo, tanto do fruto in natura quanto dos produtos derivados. Sua maior utilização está no aproveitamento na alimentação, devido ao seu grande valor nutritivo (BOAS, 2009). Ele é um fruto sazonal e possui um período de floração, frutificação e maturação de aproximadamente três meses. Portanto, existe uma carência do pequi na entressafra. Normalmente, é consumido pelas populações que habitam as regiões em que são produzidos, sendo o Estado de Minas Gerais seu principal produtor e consumidor (LIMA et al., 2007).

O pequizeiro é uma árvore de diversas utilidades desde sua madeira até seu fruto, com múltiplas aplicações, indo da indústria artesanal até à culinária regional, além de apresentar potencial de uso para a produção de combustíveis e lubrificantes. O extrato de suas folhas apresenta atividade moluscicida e antifúngica, in vitro, em diversos organismos. A indústria cosmética se beneficia das propriedades de seu óleo, tanto da polpa como da amêndoa. Porém, na culinária local 
os pratos com esse fruto são o ponto alto de interesse, com odor forte e característico (OLIVEIRA et al., 2008).

O fruto é utilizado mais frequentemente na culinária, sendo raro o seu consumo in natura. Sua polpa é utilizada na elaboração de diferentes pratos, como arroz com pequi, feijão com pequi, frango com pequi, cuscuz com pequi e o tradicional baião de três (arroz, feijão e pequi). Também é utilizado na produção de geleias, doces, ração para porcos e galinhas e na obtenção de óleo. A polpa fermentada produz um tipo de licor bastante conhecido e apreciado em algumas regiões brasileiras (OLIVEIRA et al., 2008). Usa-se a amêndoa como ingrediente de farofas, doces e paçocas, além de ser consumida salgada como petisco. Por se tratar de um fruto de fácil produção e com boas características quanto ao sabor e valor nutritivo, pode representar uma potencial fonte na alimentação e sobrevivência de uma parcela da população brasileira (RIBEIRO, 2000; ARAÚJO, 1995).

A polpa também é utilizada para combater diversos tipos de afecções, principalmente as do sistema respiratório (RAMOS et al., 2001; ALMEIDA e SILVA, 1994). O óleo é também utilizado na medicina popular para sanar problemas oftalmológicos relacionados à deficiência de vitamina $\mathrm{A}$, comprovado cientificamente devido ao seu alto teor de carotenoides com atividade provitamina $\mathrm{A}$ (ALMEIDA, COSTA e SILVA, 2008; OLIVEIRA et al., 2006).

A polpa do fruto, parte mais importante em termos de utilização, possui alto valor energético (SEGAL et al., 2006) e é onde se encontram teores médios de vitamina C (GONÇALVES et al., 2011; SANO; ALMEIDA, 1998; FRANCO, 1992). Quando cozida, há a presença de diversos carotenoides (RAMOS et al., 2001). A polpa e a amêndoa deste fruto são fontes consideráveis de minerais (OLIVEIRA et al., 2010; ALMEIDA e SILVA, 1994). Quanto às proteínas, os teores encontrados na polpa variam de 6,71\% a 13,5\%; na amêndoa, o teor varia de 24\% a 54\%; e no óleo, de $42,2 \%$ a $47 \%$ (OLIVEIRA et al., 2006).

\section{0 material obtido}

Para fins de amostragem, pesquisou-se a palavra "pequi", entre aspas para delimitar esta palavra exata, na seção "Jornal Impresso" da busca do site da Folha de S.Paulo (www.folha.com), no período de um ano (01/08/2011 a 31/07/2012).

Observou-se que o resultado da busca elencou 10 notícias, porém duas delas ("Cocaína Vendida no Brasil é 'batizada' até com vermífugo" e "Mais da metade da cocaína no Brasil tem 'DNA' boliviano") não se referiam ao fruto, mas sim a uma abreviação do termo "Perfil Químico" 
(projeto da Polícia Federal que analisa a composição drogas apreendidas pelo Brasil). Tendo em vista este outro significado, estes textos não serão levados em consideração na análise desta pesquisa.

Sobraram, assim, oito matérias que tratam do fruto pequi e serão analisadas neste artigo. Destas, três são críticas de restaurante ("Diversità aposta em menu brasileiro", "Carmen une arte e pratos brasileiros" e "Yacare faz comida pantaneira, com jacaré, pequi e piranha") e quatro são colunas gastronômicas assinadas por especialistas ("Quiabo, o tal” por Juliana Saad, "Saudosismo na cozinha" e "Comida Brasileira de verdade" por Nina Horta e "O Peru banhou de nós", por Alexandra Forbes), no caderno Comida. O último texto é referente ao caderno Turismo ("Sites ajudam viajante a aproveitar visita a BH").

Assim, sete de oito matérias estão no caderno Comida, da Folha de S.Paulo, o que indica que o prisma principal do foco midiático no pequi é seu uso na culinária. O referido caderno é semanal e circula na edição de quarta-feira da Folha. Porém, mesmo a notícia publicada no caderno Turismo (semanal, publicado às quintas-feiras) também se refere ao fruto enquanto comida peculiar da região. Neste sentido, todos os textos referem-se ao pequi enquanto elemento na gastronomia.

Um exemplo deste teor está no trecho a seguir, retirado do texto "Yacare faz cozinha pantaneira, com jacaré, pequi e piranha", em um de seus últimos parágrafos: "A cozinha é comandada pela chef paulista Neuza Riffo, 50, que passou um período se familiarizando com as receitas pantaneiras. Ela faz a galinhada, acompanhada de arroz com pequi”.

Numa segunda análise, depreende-se que em seis das oito matérias o pequi é tido como um elemento gastronômico característico do Brasil, algo regional que agora passa a ser conhecido e apreciado por todo o país.

O fragmento seguinte, do texto "Diversità aposta em menu brasileiro" alude o teor citado: "Se você escolher esse restaurante pelo sugestivo nome italiano - Diversità - talvez leve um susto ao deparar-se com ingredientes como pequi, coentro, pintado...”.

Os outros dois textos analisados destacam o pouco uso do fruto na gastronomia, o seu caráter de infrequência. Mas mesmo nestes, o fruto ainda é considerado como uma peculiaridade das comidas brasileiras, como na seguinte citação: "Os próprios brasileiros vão estranhar aquele pequi cheiroso, aquele tucupi da mandioca", do texto "Comida brasileira de verdade".

Porém, outro predicado constante quando se refere ao fruto é "desconhecido". Isso pode ser observado, por exemplo, no artigo "O Peru ganhou de nós", aqui transcrito: "Até nós 
desconhecemos o que temos. Bacuri. Filhote. Tucupi. Mocotó. Pequi. Saberia descrever isso a um estrangeiro?".

\section{As análises e as considerações}

Utilizou-se a análise de conteúdo, proposta por Bardin (2002), que, segundo a autora, consiste em:

Um conjunto de técnicas de análise das comunicações visando obter, por procedimentos, sistemáticos e objetivos de descrição do conteúdo das mensagens, indicadores (quantitativos ou não) que permitam a inferência de conhecimentos relativos às condições de produção / recepção [...] destas mensagens (BARDIN, 2002, p. 42).

Aplicou-se a teoria para verificar o foco das notícias que apareceram na busca e saber qual é o principal atrativo que a mídia observa no pequi. Neste sentido, há de se considerar “[...] a presença ou a ausência de uma dada característica de conteúdo ou conjunto de características num determinado fragmento da mensagem" (LIMA, 1993, p. 54).

Assim, ao classificar todas as notícias divulgadas como da área gastronômica, pode-se perceber que apenas esta característica é divulgada e, por consequência, a população em geral conhece apenas esta utilização do fruto, desprezando-se as outras aplicações, como medicamentos ou biocombustíveis.

Ambos os cadernos do jornal, citados na pesquisa (Comida e Turismo), ressalte-se, podem ser chamados também de "suplementos" e caracterizam-se por não terem circulação diária, mas sim semanal ou mensal (neste caso, os dois são semanais). Segundo o Manual de Redação da Folha (2008, p. 49), um caderno deste tipo precisa ter outras três particularidades: "1) tratar de assuntos de interesse específico; 2) ser voltados para públicos definidos; e 3) tratar de temas de interesse geral, mas de maneira aprofundada".

Ou seja, considerando que o fruto teve divulgação em dois suplementos semanais - Comida e Turismo -, pode-se observar que estes se enquadram nos dois primeiros pontos: assuntos de interesse específicos e voltados para públicos definidos. Aqui se depreende que, mesmo saindo na Folha de S.Paulo, o pequi não é um assunto para o grande público, mas sim "para públicos definidos" - aqueles que tivessem interesse específico em assuntos gastronômicos ou turísticos.

Verifica-se que a frequência de notícias sobre o fruto ainda pode ser considerada baixa (em torno de uma matéria a cada mês e meio) para um elemento que tem sido tão pesquisado e utilizado 
nas mais diversas formas. Além disso, divulga-se apenas a vertente da culinária (jornalismo cultural), deixando de lado os demais prismas do pequi, como a pesquisa sobre seu uso enquanto biocombustível ou em prevenção e combate de doenças.

É interessante ressaltar que, apesar das ocorrências citadas, a amostragem exemplifica como o fruto ainda é pouco divulgado na imprensa, em uma média de um texto a cada mês e meio.

Pode-se depreender que, levando-se em consideração os cadernos de publicação, não é todo o público leitor da Folha de S.Paulo que tem acesso ao conteúdo relativo ao fruto. Além disso, tendo em vista que as notícias falam apenas sobre o pequi enquanto alimento, a parte da população que já leu a seu respeito conhece apenas esta utilização, desprezando-se seus demais usos. Por fim, pela frequência de publicação, observa-se que pouco se divulga sobre o fruto.

Artigo submetido em 21/12/2012 e aceito em 24/04/2013.

\section{Referências}

ALMEIDA, S. P.; COSTA, T. S. A.; SILVA, J. A. Frutas nativas do cerrado: caracterização físicoquímica e fonte potencial de nutrientes. In: SANO, S. M.; ALMEIDA, S. P.; RIBEIRO, J. F. Cerrado: ecologia e flora. Brasília: EMBRAPA CERRADOS, 2008. p. 351-381.

ALMEIDA, S. P.; SILVA, J. A. Piqui e buriti: importância alimentar para a população dos cerrados. Planaltina: EMBRAPA-CPAC, 1994.

ARAÚJO, J. M. A. Química de alimentos: teoria e prática. Viçosa: Imprensa Universitária da Universidade Federal de Viçosa, 1995.

AVIDOS, M. F. D.; FERREIRA, L. T. Frutos do cerrado. Biotecnologia Ciência \& Desenvolvimento, Brasília, v. 3, n. 15, p. 36-41, jul./ago. 2000.

BARDIN, L. Análise de conteúdo. Tradução de Luis Antero Reto e Augusto Pinheiro. Lisboa: Edições 70, 2002.

BOAS, E. V. B. V. Caracterização de e agregação de valores a frutos do cerrado: pequi (Caryocar brasiliense Camb.), marolo (Annona crassiflora Mart.), gariroba (Campomanesia xanthocarpa) e pitaia ("saborosa" - Selenicereus setaceus Rizz.). 2009. 39 f. Projeto de Pesquisa e Plano de Trabalho (Programa Pesquisador Mineiro (PPM)). Lavras: Universidade Federal de Lavras, 2009.

DIAS, B. F. S. Alternativas de desenvolvimento dos cerrados: manejo e conservação dos recursos naturais renováveis. Brasília: FUNATURA, 1992.

FRANCO, G. Tabela de composição química de alimentos. 9. ed. Rio de Janeiro: Atheneu, 1992. 
GONÇALVES, G. A. S. et al. Qualidade dos frutos do pequizeiro submetidos a diferentes tempos de cozimento. Ciência e Agrotecnologia, Lavras, v. 35, n. 2, p. 377-385, mar./abr. 2011.

KERR, W. E.; SILVA, F. R.; TCHCARRAMAE, B. Pequi (Caryocar brasiliense Camb.): informações preliminares sobre um pequi sem espinhos no caroço. Revista Brasileira de Fruticultura, Jaboticabal, v. 29, n. 1, p. 169-171, abr. 2007.

LIMA, A. Caracterização química, avaliação da atividade antioxidante in vitro e in vivo, e identificação dos compostos fenólicos presentes no pequi (Caryocar brasiliense, Camb.). 2008. 182 f. Tese (Doutorado) - Faculdade de Ciências Farmacêuticas, Universidade de São Paulo, São Paulo, 2008.

LIMA, A. et al. Composição química e compostos bioativos presentes na polpa e amêndoa do pequi (Caryocar brasiliense, Camb.). Revista Brasileira de Fruticultura, Jaboticabal, v. 29, n. 3, p. 695698, dez. 2007.

LIMA, M. A. D. S. Análise de Conteúdo: estudo e aplicação. Logos Revista de Divulgação Científica da Ulbra, Canoas, v. 5, n. 1, p. 53-58, 1993.

MANUAL de redação. Folha de S.Paulo, São Paulo, 2008. Publifolha.

OLIVEIRA, M. E. B. et al. Características químicas e físico-químicas de pequis da Chapada do Araripe, Ceará. Revista Brasileira de Fruticultura, Jaboticabal, v. 32, n. 1, p. 114-125, mar. 2010.

OLIVEIRA, M. E. B. et al. Aspectos agronômicos e de qualidade do pequi. Fortaleza: Embrapa Agroindústria Tropical, 2008.

OLIVEIRA, M. N. S. et al. Estádio de maturação dos frutos e fatores relacionados aos aspectos nutritivos e de textura da polpa de pequi. Revista Brasileira de Fruticultura, Jaboticabal, v. 28, n. 3, p. 380-386, dez. 2006.

PROENÇA, C.; OLIVEIRA, R. S.; SILVA, A. P. Flores e frutos do cerrado. 2. ed. Brasília: Rede de Sementes do Cerrado, 2006.

RAMOS, M. I. L. et al. Efeito do cozimento convencional sobre os carotenóides pró-vitamínicos 'A' da polpa do piqui (Caryocar brasiliense Camb). Boletim do Centro de Pesquisa de Processamento de Alimentos (CEPPA), Curitiba, v. 19, n. 1, p. 23-32, jan./jun. 2001.

RIBEIRO, R. F. Pequi: o rei do cerrado. Belo Horizonte: Rede Cerrado, 2000.

SANO, S. M.; ALMEIDA, S. P. Cerrado: ambiente e flora. Platina: Embrapa-CPAC, 1998.

SEGAL, S. D. et al. Triacylglycerol analysis of pequi (Caryocar brasiliensis Camb.) oil by electrospray and tandem mass spectrometry. Journal of the Science of Food and Agriculture, London, v. 86, p. 445-452, 2006.

SILVA, M. R. et al. Caracterização química de frutos nativos do cerrado. Ciência Rural, Santa Maria, v. 38, n. 6, p. 1790-1793, set. 2008. 